\title{
Spinal anesthesia after intraoperative cardiac arrest during general anesthesia in an infant
}

This article was published in the following Dove Press journal:

Local and Regional Anesthesia

31 March 2017

Number of times this article has been viewed

\section{Emmett E Whitaker ${ }^{1,2}$ \\ Veronica Miler ${ }^{1,2}$ \\ Jason Bryant ${ }^{1,2}$ \\ Stephanie Proicou' \\ Rama Jayanthi ${ }^{3,4}$ \\ Joseph D Tobias ${ }^{1,2}$}

'Department of Anesthesiology \& Pain Medicine, Nationwide Children's Hospital, ${ }^{2}$ Department of Anesthesiology \& Pain Medicine, The Ohio State University College of Medicine, ${ }^{3}$ Division of Pediatric Urology, Nationwide Children's Hospital, ${ }^{4}$ Department of Urology, The Ohio State University College of Medicine, Columbus, $\mathrm{OH}$, USA
Correspondence: Emmett E Whitaker Department of Anesthesiology \& Pain Medicine, Nationwide Children's Hospital, 700 Children's Drive, Columbus, $\mathrm{OH} 43205$, USA

$\mathrm{Tel}+\mathrm{I} 6147224200$

Fax + I 6147224203

Email: Emmett.whitaker@

nationwidechildrens.org
Abstract: Although generally safe and effective, severe perioperative complications, including cardiac arrest, may occur during general anesthesia in infants. With the emergence of evidence that specific anesthetic agents may affect future neurocognitive outcomes, there has been an increased focus on alternatives to general anesthesia, including spinal anesthesia. We present a case of cardiac arrest during general anesthesia in an infant who required urologic surgery. During the subsequent anesthetic care, spinal anesthesia was offered as an alternative to general anesthesia. The risks of severe perioperative complications during general anesthesia are reviewed, etiologic factors for such events are presented, and the use of spinal anesthesia as an alternative to general anesthesia is discussed.

Keywords: child, pediatric anesthesia, complications

\section{Introduction}

In 1899, August Bier reported the successful use of spinal anesthesia in an 11-yearold child during excision of a tumor on the thigh. ${ }^{1}$ This initial report was followed by the publication in the early 1900s of two case series regarding the use of spinal anesthesia in infants and children. ${ }^{2,3}$ However, despite its popularity in adults, the technique never gained great popularity in pediatric anesthesia until the 1980s when it was shown to be a suitable alternative to general anesthesia in the high-risk, former preterm neonate..$^{4-9}$ In this population, spinal anesthesia was suggested as a means of limiting the incidence of postoperative complications, especially apnea and respiratory insufficiency, which were noted following general anesthesia with halothane. ${ }^{10}$ However, once again the enthusiasm waned as the risk of apnea was shown to be limited with the new volatile anesthetic agents, sevoflurane and desflurane. ${ }^{11,12}$ The resurgence in popularity of spinal anesthesia has occurred for a number of reasons that are not limited to postoperative apnea.

New medications, improved monitoring modalities, and advancements in pediatric anesthesiology training have all contributed to the safety of contemporary pediatric anesthesia practice. However, despite these issues, perioperative cardiac arrest may occur during anesthetic care. Age is one of the several risk factors that has been repeatedly noted to be associated with an increased risk of perioperative cardiac arrest. ${ }^{13-18}$ More recently, concern has been expressed, based on animal models and retrospective cohort studies, regarding the potential neurocognitive effects of general anesthesia during neonatal period of infancy. ${ }^{19-21}$ Despite reassuring results from recent, prospective clinical trials in Sun et al, ${ }^{22}$ there has been a renewed interest in the use of spinal 
anesthesia as a means of avoiding general anesthesia during the potentially vulnerable time period. ${ }^{23-25}$

We present a case of cardiac arrest during general anesthesia in an infant who required urologic surgery. During the subsequent anesthetic care, spinal anesthesia was offered as an alternative to general anesthesia. The risks of severe perioperative complications during general anesthesia are reviewed, etiologic factors for such events are presented, and the use of spinal anesthesia as an alternative to general anesthesia is discussed.

\section{Case report}

According to the Nationwide Children's Hospital Institutional Review Board (Columbus, OH, USA), approval is not required for presentation of single case report. The child's parents provided written informed consent for the publication of this case report.

At the time of the initial surgery, the patient was an 8-month-old, $9.4 \mathrm{~kg}$ boy scheduled for diagnostic laparoscopy and bilateral orchidopexy. The patient had a known history of proximal hypospadias and bilateral nonpalpable testes, but was otherwise well. He had no allergies. His medication history was significant only for cetirizine, which he took for seasonal allergies. Preoperative laboratory studies were not performed. His vital signs on the morning of the procedure were unremarkable, and the child had been NPO for 5 hours (clear liquids) and $>8$ hours for solids. The patient underwent an uneventful inhalation induction with the incremental administration of sevoflurane up to $8 \%$ in $100 \%$ oxygen. A 22-gauge peripheral intravenous catheter was placed in the right foot and propofol $(50 \mathrm{mg}$ ) was administered intravenously to deepen the level of anesthesia and allow for endotracheal intubation without the use of a neuromuscular blocking agent. Direct laryngoscopy followed by endotracheal intubation with a $4.0 \mathrm{~mm}$ cuffed tracheal tube was performed without difficulty. Transition to maintenance anesthesia with isoflurane was initiated. Isoflurane was used for maintenance of anesthesia to minimize cost to the patient and to provide smooth emergence. Fentanyl $(2.5 \mu \mathrm{g} / \mathrm{kg})$ and dexamethasone $(0.5 \mathrm{mg} / \mathrm{kg})$ were administered intravenously. The first 35 minutes under general anesthesia were uneventful. A $5 \mathrm{~mm}$ port was placed in the umbilicus using an open technique. A Veress needle was not used. Coincident with the initiation of insufflation for laparoscopy, there was a sudden and marked decrease in the end-tidal carbon dioxide $\left(\mathrm{ETCO}_{2}\right)$ as well as a progressive decrease in heart rate and exhaled tidal volume. At this time, the end-tidal isoflurane concentration was $1.1 \%$.
Glycopyrrolate $(0.1 \mathrm{mg})$ was administered intravenously while breath sounds were auscultated. It was determined that an endobronchial intubation had occurred. The $\mathrm{ETCO}_{2}$, heart rate, and tidal volumes recovered as the endotracheal tube was repositioned. It was also noted that, during the event, there was a loss of the pulse oximeter plethysmograph waveform, which recovered with the increase in heart rate and $\mathrm{ETCO}_{2}$ after repositioning of the endotracheal tube. Laparoscopic findings included bilateral intra-abdominal testes, and the total laparoscopy time was $\sim 5$ minutes. The laparoscopy port was removed and the umbilical incision closed. A left inguinal incision was made, the abdomen entered, and an initial mobilization of the testis begun. Approximately 10 minutes later, there was again a sudden and marked decrease in $\mathrm{ETCO}_{2}$, an erratic heart rate with precipitous bradycardia, and loss of pulse oximeter plethysmograph waveform. At this time, the end-tidal isoflurane concentration was $0.7 \%$. Atropine $(0.1 \mathrm{mg})$ was administered intravenously and chest compressions were initiated with return of spontaneous circulation in $<1$ minute. Surgery was suspended (the inguinal incision rapidly closed with the testis left in the inguinal canal) and the patient was observed in the operating room. An intra-operative chest radiograph was normal. The surgical procedure was cancelled, the patient's trachea was left intubated, and he was transferred to the pediatric intensive care unit for further management and evaluation. With the discontinuation of the anesthetic agents, the patient quickly regained consciousness and his trachea was extubated shortly after arrival to the pediatric intensive care unit. His vital signs and physical examination were normal.

A postoperative electrocardiogram and echocardiogram were normal, as were a complete blood count and comprehensive metabolic profile. The patient was found to have a positive nasal swab for coronavirus, adenovirus, and enterovirus, though he exhibited no symptoms of a viral infection. He was discharged to home 24 hours later with no obvious untoward sequelae. A follow-up with pediatric cardiology revealed no evidence of structural or functional heart disease, and they recommended no further evaluation. The patient was scheduled to return for the previously cancelled surgical procedure (open bilateral orchidopexy) 3 months later at the age of 11 months. Given that the patient's cardiac arrest did not have a clear etiology, the surgical team and parents were interested in alternatives to general anesthesia for this medically-indicated surgery. At Nationwide Children's Hospital, given the concerns for the potential neurocognitive effects of general anesthesia in infants, a busy spinal 
anesthesia program has been developed. The parents were enthusiastic about the possibility of avoiding general anesthesia and informed consent was obtained for spinal anesthesia. On the morning of presentation for the second surgery, the patient's weight was $10.3 \mathrm{~kg}$ and his vital signs were normal. There was no history of recent viral illness and the patient appeared well. In the preoperative area, $\mathrm{LMX}^{\circledR}$ cream $(4 \%$ topical lidocaine; Ferndale Laboratories Inc, Ferndale, MI, USA) was applied to the lumbar area to minimize discomfort with the placement of the spinal needle. After arrival to the operating room, the patient was placed in the sitting position. After sterile preparation, the intrathecal space was accessed on the first attempt, using a 1.5-inch, 22-gauge spinal needle. Upon return of cerebrospinal fluid, $1 \mathrm{~mL}$ of $0.5 \%$ isobaric bupivacaine containing clonidine $(10 \mu \mathrm{g})$ was administered. We typically add clonidine to the local anesthetic in order to provide long-lasting pain relief after surgery. The patient was then placed in the supine position, standard American Society of Anesthesiologists' monitors were placed, and a 22-gauge peripheral intravenous catheter was placed in the left foot. Immediate motor and sensory block were noted. The surgery was started and initial operating conditions were excellent. Due to the patient's irritability, a single dose of dexmedetomidine $(7.5 \mu \mathrm{g})$ was administered intravenously during the first 15 minutes of the procedure. Dexmedetomidine is our first-line sedative of choice (if sedatives are needed) due to its minimal respiratory depression. Thereafter, the surgery (bilateral inguinal orchidopexy) was able to be completed with excellent operating conditions. The patient was hemodynamically stable throughout the operation, which lasted $\sim 1$ hour and 25 minutes. He required no further sedation. His post-anesthesia care unit stay was uncomplicated, and he was discharged to home that afternoon without incident.

\section{Discussion}

The incidence of cardiac arrest in pediatric patients undergoing general anesthesia has been reported as 1.4 per 10,000, with only $28 \%$ surviving to hospital discharge. ${ }^{15}$ Risk factors have included younger age, higher American Society of Anesthesiologists' physical status, emergency surgery, and patients with congenital heart disease, especially those with pulmonary hypertension. Of the 150 cardiac arrests reported in the initial Perioperative Cardiac Arrest registry, medication-related (37\%) and cardiovascular (32\%) causes were the most common, together accounting for $69 \%$ of all arrests. ${ }^{15}$ Cardiovascular depression from halothane, alone or in combination with other medications, was responsible for two-thirds of all medication-related arrests, being the most common etiologic factor identified. With the transition from halothane to sevoflurane for the inhalational induction of anesthesia, there was a shift noted in the Perioperative Cardiac Arrest registry regarding the etiology of perioperative cardiac arrest. ${ }^{16}$ Medication-related cardiac arrests accounted for $18 \%$ of all arrests, compared with $37 \%$ from the previous survey. ${ }^{15,16}$ Cardiovascular causes of cardiac arrest are now the most common ( $41 \%$ of all arrests), with hypovolemia from blood loss and hyperkalemia from the rapid transfusion of blood being the most commonly identified etiologies.

In our patient, there were several potential etiologic factors which may have been responsible for the sudden hemodynamic deterioration. In the pediatric population in general, airway events with hypoxemia remain the most common etiology of bradycardia. However, in our patient, there was no change in oxygen saturation until after the development of bradycardia and decreased cardiac output. Although generally demonstrated to be safer than halothane, sevoflurane or isoflurane can result in negative inotropic and chronotropic effects, especially with higher inhaled concentrations. ${ }^{26,27}$ These effects may be magnified by the administration of other medications with negative inotropic and chronotropic effects, such as propofol, or in the setting of hypovolemia related to a prolonged preoperative period of fasting. ${ }^{28}$ At the time of these events, the end-tidal isoflurane concentration was well within the concentrations routinely used for maintenance anesthesia (1.1\% and $0.7 \%)$ and therefore unlikely to be the primary etiology of the cardiovascular decompensation. The first episode of bradycardia occurred during the initial insufflation for laparoscopy. Although bradycardia may occur in relation to augmentation of vagal afferents during insufflation, and preload may decrease in relation to the increased intra-abdominal pressure, such profound hemodynamic changes are uncommon with laparoscopy. ${ }^{29-31}$ Furthermore, a second intraoperative episode occurred after laparoscopy and insufflation were discontinued. Other less common etiologic factors which may lead to such intraoperative complications, such as inherited or acquired cardiac diseases, were ruled out postoperatively by our pediatric cardiology colleagues as our patient had a normal echocardiogram and a normal electrocardiogram.

Given the lack of a clear etiologic event in our patient, the option of proceeding with spinal anesthesia was discussed and offered to the parents when our patient returned. As the decision was made to proceed with spinal anesthesia, the surgical procedure was converted to an open procedure given 
the potential respiratory effects of insufflation without airway control and mechanical ventilation. The obvious concern regarding the use of spinal anesthesia in this scenario was the potential for adverse effects on hemodynamic function. However, spinal anesthesia (even high blockade) has limited effects on hemodynamic function in infants and children $<6$ years of age. ${ }^{32-34}$ This has traditionally been attributed to the incomplete development of the sympathetic nervous system in infants. ${ }^{34}$ However, analysis of heart rate variability during the administration of spinal anesthesia in infants suggests that the reflex response to high spinal anesthesia is a primarily diminished parasympathetic tone that offsets the blockade of sympathetic function. ${ }^{35}$ In our patient, no clinically significant changes in heart rate, blood pressure, or oxygen saturation were noted after the administration of spinal anesthesia. Despite these data, the potential for hemodynamic changes should always be considered and appropriate monitoring employed with ready access to resuscitation medications if needed. For obvious reasons, we selected spinal anesthesia in the patient due to spinal anesthesia's remarkable cardiovascular stability, which has been well documented.

With a well-trained, multidisciplinary team of pediatric anesthesiologists, surgeons, and nursing staff, the use of spinal anesthesia in these high-risk patients and the general population will be met with high patient safety outcomes and parent satisfaction. Given our center's extensive experience with spinal anesthesia, we are comfortable and facile with the placement of an intravenous cannula in an anesthetized foot or leg after the placement and onset of spinal anesthesia. The safety of this practice is supported by the limited or absent incidence of hemodynamic changes related to spinal anesthesia in infants. This practice is the same as that followed by the only other center in the US with a large spinal anesthesia program (Dr R Williams, The University of Vermont, personal communication, September, 2015). The authors would not suggest or condone such a practice in the absence of significant experience with spinal anesthesia in neonates and infants.

Spinal anesthesia in high-risk pediatric patients has been described in prior studies, but the focus of these studies has been avoidance of apnea in ex-preterm infants or, more recently, as a means of avoiding the potential negative neurocognitive effects of general anesthetic agents. Spinal anesthesia is appropriate in many cases where avoidance of general anesthesia is desired, regardless of the reason. In our patient, spinal anesthesia provided several advantages, including intraoperative hemodynamic stability, effective surgical anesthesia, elimination of the need for opioids or inhalation anesthetic agents, patient immobility, and adequate operating conditions without the use of neuromuscular blocking agents. ${ }^{32-34,36,37}$

\section{Disclosure}

The authors report no conflicts of interest in this work.

\section{References}

1. Bier A. Experiment regarding the cocainization of the spinal cord. Zentralbl Chir. 1899;51:361-369.

2. Bainbridge WS. A report of twelve operations on infants and young children during spinal anesthesia. Arch Pediatr. 1901;18:570-574.

3. Tyrell-Gray H. A study of spinal anaesthesia in children and infants. Lancet. 1909;2:913-917.

4. Abajian JC, Mellish RWP, Browne AF, et al. Spinal anesthesia for surgery in the high-risk infant. Anesth Analg. 1984;63(3):359-362.

5. Sartorelli KH, Abajian JC, Kreutz JM, Vane DW. Improved outcome utilizing spinal anesthesia in high-risk infants. J Pediatr Surg. 1992;27(8): 1022-1025.

6. Veverka TJ, Henry DN, Milroy MJ, et al. Spinal anesthesia reduces the hazard of apnea in high-risk infants. Am Surg. 1991;57(8):531-534.

7. Harnik EV, Hoy GR, Potolicchio S, Stewart DR, Siegelman RE. Spinal anesthesia in premature infants recovering from respiratory distress syndrome. Anesthesiology. 1986;64(1):95-99.

8. Webster AC, McKishnie JD, Kenyon CF, Marshall DG. Spinal anaesthesia for inguinal hernia repair in high-risk neonates. Can J Anaesth. 1991;38(3):281-286.

9. Blaise GA, Roy WL. Spinal anaesthesia for minor paediatric surgery. Can Anaesth Soc J. 1986;33(2):227-230.

10. Welborn LG, Rice LJ, Hannallah RS, Broadman LM, Ruttimann UE, Fink R. Postoperative apnea in former preterm infants: prospective comparison of spinal and general anesthesia. Anesthesiology. 1990;72(5):838-842.

11. Sale SM, Read JA, Stoddart PA, Wolf AR. Prospective comparison of sevoflurane and desflurane in formerly premature infants undergoing inguinal herniotomy. Br J Anaesth. 2006;96(6):774-778.

12. William JM, Stoddart PA, Williams SA, WolfAR. Post-operative recovery after inguinal herniotomy in ex-premature infants: comparison between sevoflurane and spinal anaesthesia. Br J Anaesth. 2001;86(3):366-371.

13. Flick RP, Sprung J, Harrison TE, et al. Perioperative cardiac arrests in children between 1988 and 2005 at a tertiary referral center: a study of 92,881 patients. Anesthesiology. 2007;106(2):226-237.

14. van der Griend BF, Lister NA, McKenzie IM, et al. Postoperative mortality in children after 101,885 anesthetics at a tertiary pediatric hospital. Anesth Analg. 2011;112(6):1440-1447.

15. Morray JP, Geiduschok JM, Ramamoorthy C, et al. Anesthesia-related cardiac arrest in children: initial findings of the Pediatric Perioperative Cardiac Arrest (POCA) Registry. Anesthesiology. 2000;93(1):6-14.

16. Bhananker SM, Ramamoorthy C, Geiduschek JM, et al. Anesthesiarelated cardiac arrest in children: update from the Pediatric Perioperative Cardiac Arrest Registry. Anesth Analg. 2007;105:344-350.

17. Lian C, Xie Z, Wang Z, et al. Pediatric preoperative risk factors to predict postoperative ICU admission and death from a multicenter retrospective study. Paediatr Anaesth. 2016;26(6):637-643.

18. Fiadjoe JE, Nishisaki A, Jagannathan N, et al. Airway management complications in children with difficult tracheal intubation from the Pediatric Difficult Intubation (PeDI) registry: a prospective cohort analysis. Lancet Respir Med. 2016;4(1):37-48.

19. Davidson AJ. Anesthesia and neurotoxicity to the developing brain: the clinical relevance. Pediatr Anesth. 2011;21(7):716-721.

20. McGowan FX Jr, Davis PJ. Anesthetic-related neurotoxicity in the developing infant: of mice, rats, monkeys and, possibly, humans. Anesth Analg. 2008;106(6):1599-1602. 
21. Blaylock M, Engelhardt T, Bissionnette B. Fundamentals of neuronal apoptosis relevant to pediatric anesthesia. Pediatr Anesth. 2010; 20(5):383-395.

22. Sun LS, Li G, Miller TL, et al. Association Between a Single General Anesthesia Exposure Before Age 36 Months and Neurocognitive Outcomes in Later Childhood. JAMA. 2016;315(21):2312-2320.

23. Davidson AJ, Morton NS, Arnup SJ, et al. Apnea after Awake Regional and General Anesthesia in Infants: The General Anesthesia Compared to Spinal Anesthesia Study--Comparing Apnea and Neurodevelopmental Outcomes, a Randomized Controlled Trial. Anesthesiology. 2015;123(1):38-54.

24. Frawley G, Bell G, Disma N, et al. Predictors of Failure of Awake Regional Anesthesia for Neonatal Hernia Repair: Data from the General Anesthesia Compared to Spinal Anesthesia Study--Comparing Apnea and Neurodevelopmental Outcomes. Anesthesiology. 2015;123(1): 55-65.

25. Williams RK, Black IH, Howard DB, et al. Cognitive outcome after spinal anesthesia and surgery during infancy. Anesth Analg. 2014;119(3): 651-660.

26. Kataria B, Epstein R, Bailey A, et al. A comparison of sevoflurane to halothane in paediatric surgical patients: results of a multicentre international study. Paediatr Anaesth. 1996;6(4):283-292.

27. Green DH, Townsend P, Bagshaw O, Stokes MA. Nodal rhythm and bradycardia during inhalation induction with sevoflurane in infants: a comparison of incremental and high-concentration techniques. $\mathrm{Br} J$ Anaesth. 2000;85(3):368-370.

28. Tramèr MR, Moore RA, McQuay HJ. Propofol and bradycardia: causation, frequency and severity. Br J Anaesth. 1997;78(6):642-651.
29. Aghamohammadi H, Mehrabi S, Mohammad Ali Beigi F. Prevention of bradycardia by atropine sulfate during urological laparoscopic surgery: a randomized controlled trial. Urol J. 2009;6(2):92-95.

30. Tobias JD, Holcomb GW 3rd, Brock JW 3rd, Deshpande JK, Morgan WM 3rd. Cardiorespiratory changes in children during laparoscopy. J Pediatr Surg. 1995;30(1):33-36.

31. Tobias JD. Anesthetic considerations for laparoscopy in children. Semin Laparosc Surg. 1998;5(1):60-66.

32. Dohi S, Naito H, Takahashi T. Age-related changes in blood pressure and duration of motor blockade in spinal anesthesia. Anesthesiology. 1979;50(4):319-323.

33. Finkel JC, Boltz MG, Conran AM. Haemodynamic changes during high spinal anaesthesia in children having open heart surgery. Paediatr Anaesth. 2003;13(1):48-52.

34. Oberlander TF, Berde CB, Lam KH, Rappaport LA, Saul JP. Infants tolerate spinal anesthesia with minimal overall autonomic changes: analysis of heart rate variability in former premature infants undergoing hernia repair. Anesth Analg. 1995;80(1):20-27.

35. Assali NS, Brinkman CR 3rd, Woods JR Jr, Dandavino A, Nuwayhid B. Development of neurohumoral control of fetal, neonatal, and adult cardiovascular functions. Am J Obstet Gynecol. 1977;129(7):748-759.

36. Kokki H, Heikkinen M, Ahonen R. Recovery after paediatric daycase herniotomy performed under spinal anaesthesia. Pediatr Anesth. 2000; 10(4):413-417.

37. Ecoffey C, Lacroix F, Giaufré E, et al. Epidemiology and morbidity of regional anesthesia in children: a follow-up one-year prospective survey of the French-Language Society of Pediatric Anesthesiologists (ADARPEF). Paediatr Anaesth. 2010;20(12):1061-1069.
Local and Regional Anesthesia

\section{Publish your work in this journal}

Local and Regional Anesthesia is an international, peer-reviewed, open access journal publishing on the development, pharmacology, delivery and targeting and clinical use of local and regional anesthetics and analgesics. The journal is included in PubMed, and welcomes submitted papers covering original research, basic science, clinical studies,

\section{Dovepress}

reviews and evaluations, guidelines, expert opinion and commentary, case reports and extended reports. The manuscript management system is completely online and includes a very quick and fair peer-review system, which is all easy to use. Visit http://www.dovepress.com/ testimonials.php to read real quotes from published authors. 